Methods we determine statistic quintiles of frequency rates indicators and the extent of their severity based on ILO proposed statistics to assess rates by the top 17 sectors of the economy to the entire worker population during the 2009-2011 time period. We calculate injury, mortality and lethality rates observing lower and upper limits across three year's time-trends. We identify sectors that persist the period at top and give a score value to be rank.

Results The impact rate shows severe seriousness for the highest injury rate quintile, which bears 5.61 times the lowest risk quintile, and its economic activities have 3 times more risk of suffering injuries compared with the rest. Time trend indicates that the number of workers exposed to it decreases by $10 \%$ in 2011. $43 \%$ of workers are included in the last but one quintile of mortality. The highest lethality risk quintile and the second next concentrate more than $55 \%$ of workers. We identified 10, 8 and 5 every 17 economic activities that respectively persist within the worst injury, mortality and lethality risk in the period analysed. Eight sectors are repeated in at least 2 of those rates. By the score method, we found the same results.

Conclusion This paper emphasises the importance and potential of routine statistics use in all areas of occupational safety and health research to increase their scope and effectiveness, and the identification and implementation of preventive measures from a simple, current, reliable and easy to use method for more inclusive public health policies.

\section{DOES WORK RELATEDNESS OF AN INJURY INFLUENCE TIME ON DISABILITY BENEFITS IN BRAZIL, A COHORT STUDY}

1I A Steenstra, '1brahim, ${ }^{2}$ Branco. 'Institute for Work and Health, Toronto, Canada; ${ }^{2}$ University of Brasilia, Brasilia, Brazil

\subsection{6/oemed-2013-101717.74}

Objectives Evidence on predictors of time on benefits is mainly from developed countries. Evidence from emerging economies is lacking. In this cohort study predictors for time on disability benefits were identified within a Brazilian workers compensation insurance. Workers can claim benefits for either work related or work relevant conditions. This provided us with the unique opportunity to examine the role of work relatedness of back pain on time on benefits

Methods In 2008, 83,114 workers diagnosed with back pain were claiming benefits. Claimants had $>15$ days away from work. The analysis was adjusted for sex, age (/ 10 year), back pain benefits in 2007, claim rate of the industrial sector in 2007, and ICD-10 diagnosis (as agreed by two physicians). Duration of follow up was 52 weeks. Predictors for time on benefits in the first episode were identified by means of Cox regression analysis. Explained variance and c-statistic were calculated.

Results Median time on benefits was 55 days (Inter Quartile Range (IQR) $=33-86)$. 1.49\% of workers was on benefits after 52 weeks. Work relatedness of the claim was associated with the outcome: those with a non work related claim returned to work 1.04 times faster compared to those with a work related condition. Only age and diagnosis had hazard rate ratios over 1.2. Explained variance of the model was 3\% (c-statistic $<0.6$ ).

Conclusions Work relatedness is weakly associated with the outcome. The factors in this database have little explanatory power. More information on factors like: functional status, pain, recovery expectations, availability of workplace accommodations, physical demands and health care use might result in prediction that has utility in risk stratification an referral to early and appropriate intervention. In large administrative databases, statistical significance is easily attained therefore relevance criteria should be given and model fit should always be reported.

\section{Session: J. Respiratory epidemiology

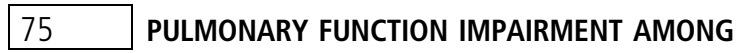 HOSPITAL SANITARY WORKERS}

Dr Fahim. Ismailia, Egypt

10.1136/oemed-2013-101717.75

Objective To assess pulmonary function and symptoms among the hospital sanitary workers.

Methods A cross sectional comparative study was conducted to compare the pulmonary function among 44 sanitary workers [exposed group] as compared to 57 workers of the administrative departments [un-exposed group] at the general public hospital. An interview questionnaire was introduced to all study participants to obtain demographic data, respiratory symptoms, and smoking history. The pulmonary function parameters; Forced Vital Capacity [FVC], Forced Expiratory Volume in 1 second $\left[\mathrm{FEV}_{1}\right]$, and Forced Expiratory Flow $\left[\mathrm{FEF}_{25-75}\right]$ and Peak Expiratory Flow $[\mathrm{PEF}]$ were determined according to the American Thoracic Society criteria. The difference between variables of the two groups was done using Independent t-Test and ChiSquare test for quantitative and qualitative variables respectively. Statistical significance was set at $(\mathrm{p}<0.05)$.

Results The mean age was $41.3 \pm 6.7$, and $41.2 \pm 7.2$ among the sanitary workers and the un-exposed workers of administrative departments $(\mathrm{p}=0.471)$. Sixteen sanitary workers were smokers (36.4\%), while $21.1 \%$ of administrative workers were smokers with no statistically significant difference between the two groups $(\mathrm{p}=0.088)$. Sanitary workers had more complaints of productive cough $(27.2 \%)$ as compared to $15.7 \%$ of the unexposed group $(\mathrm{p}=0.158)$. Among sanitary workers 33\% reported wheezing and $24 \%$ dyspnea. These symptoms were higher in the exposed group compared to the un-exposed group $(\mathrm{p}=0.031$ and $\mathrm{p}=0.011$ respectively). Among the sanitary workers, the mean [predicted values] of $\mathrm{FEV}_{1} / \mathrm{FVC}, \mathrm{PEF}$ and $\mathrm{FEF}_{25-75}$ were lower than the un-exposed group with statistically significant difference $(\mathrm{p}=0.0001, \mathrm{p}=0.0001$ and $\mathrm{p}=0.0006$ respectively). Conclusions Employment in hospital sanitary service was found to be associated with increased respiratory symptoms and decline in some of the pulmonary function parameters. Further research is needed to identify the specific exposures and work tasks responsible for increased respiratory symptoms and nature of pulmonary dysfunction in sanitary/cleaning workers in hospitals.

\section{INVESTIGATION OF THE CORRELATION BETWEEN VARIOUS AIR POLLUTION METRICS AND EFFECTS ON ASTHMA; A TIME SERIES STUDY IN SOUTHERN SWEDEN}

${ }^{1} \mathrm{~T}$ T Taj, ${ }^{1} \mathrm{~K} J$ Jakobsson, ${ }^{2} \mathrm{~A}$ Oudin. ${ }^{1}$ Lund University, Lund, Sweden; ${ }^{2}$ Umea University, Umea, Sweden

\subsection{6/oemed-2013-101717.76}

Introduction Different metrics of daily levels of particulate matter were used to study the association between air pollution and 
primary health care visits of asthma sufferers in an area with air pollution levels well within the standard air quality guidelines.

Methods Hourly readings of ambient particulate matter $\left(\mathrm{PM}_{10}, \mathrm{PM}_{2.5}\right)$, nitrogen dioxide $\left(\mathrm{NO}_{2}\right)$, nitrogen oxide $(\mathrm{NO})$, ozone $\left(\mathrm{O}_{3}\right)$ and sulphur dioxide $\left(\mathrm{SO}_{2}\right)$ from the Swedish Meteorological and Hydrological Institute (SMHI) from 2005 to 2010 were used. Six different metrics were created from these hourly readings: (1) daily 1 -h maximum; (2) 24-h average; (3) commuting-period; (4) daytime average; (5) night-time average; and (6) the daily 8 -h maximum. Outcome data were obtained from a regional health care database, covering approximately half a million people living in Malmö and neighbouring municipalities. Poisson generalised linear models were used to examine the relations between daily primary health care (PHC) visits due to asthma and air pollution metrics with different time lags.

Results Air pollutant levels throughout the study period remained well within the WHO air quality guidelines $\left(\mathrm{PM}_{10}\right.$ daily mean of $16.4 \mu \mathrm{g} / \mathrm{m}^{3}$ ). A consistent relation between daily PM levels and PHC visits due to asthma was observed for all metrics. An increased risk of $11 \%$ was found with every 10 -unit increase in daily mean levels of $\mathrm{PM}_{10}$. Commuting-period and daytime concentrations of $\mathrm{PM}_{10}$ were also associated with increased risks, of $10 \%$ and $9 \%$, respectively. The increased risk was moderate for the 8 -hour $(8 \%)$ and night-time $(7 \%)$ metrics. The lowest risk was observed for the 1 -hour maximum value $(3 \%)$.

Conclusions The results suggest that air pollution has adverse effects on respiratory health, even at very low concentrations. A significant variation in risk was observed during the day depending on the metric used. The results of this study highlight the need to re-assess air quality guidelines.

\section{RELEVANCE OF EXPOSURE TO CLEANING AGENTS BEYOND CLEANING PROFESSIONALS: PRIVATE HOMES AND HEALTHCARE WORKERS}

${ }^{1} \mathrm{~N}$ Le Moual, ${ }^{1}$ Bédard, 'Dumas, 'Varraso, 'Kauffmann, ${ }^{2}$ Zock. 'Inserm, Villejuif, France; ${ }^{2}$ CREAL, IMIM, Barcelona, Spain

\subsection{6/oemed-2013-101717.77}

Workplace and home exposures to cleaning products constitute an emerging health issue. The aim is to address the potential adverse role of exposure to cleaning agents on asthma in private homes and healthcare workers. Regarding healthcare workers, recent publications showed that they may be exposed to high level of cleaning products. As a cause of concern, they underestimated their exposures and appeared as a high risk group for asthma. Regarding home cleaning, two studies have published on this topic and suggested a deleterious role of the frequent use of cleaning sprays on asthma activity and incidence. One of them suggested a possible avoidance of spray use by women with asthma.

More recently, in a nested case-control survey on asthma of French women from the 'Etude Epidémiologique auprès des femmes de la MGEN' (E3N study), we investigated the association between self-reported weekly use of cleaning products (evaluated as previously) and current asthma among 570 women (235 with current asthma and 335 without asthma; 68 years, $59 \%$ never smokers). A positive association was suggested between weekly use of at least one spray and current asthma (odds ratio [95\% confidence interval] adjusted for age, diploma, body mass index and smoking status: 1.45 [0.94-2.24], $\mathrm{p}=$ 0.09), with a significant association in women without cleaning help (1.86 [1.04-3.33]). Avoidance of polluted places was significantly more frequent in women with current asthma who had at least two symptoms.

Domestic exposure to cleaning sprays may represent an important public health issue especially in women and it may be important to limit their use. Female hospital workers are exposed to numerous cleaning products at high risk for asthma. Selection bias may be important for both domestic and workplace exposures. More work is needed to identify the underlying mechanism (allergic or non-allergic) and to have accurate estimates of cleaning agents.

\section{THE CHANGING EPIDEMIOLOGY OF SILICOSIS IN SOUTH AFRICAN GOLD MINING - AN INDUSTRY WIDE STUDY}

${ }^{1} \mathrm{D}$ H Knight, ${ }^{2}$ Ehrlich, ${ }^{3}$ Fielding, ${ }^{3}$ Jeffery, ${ }^{3}$ Grant, ${ }^{4}$ Churchyard. ${ }^{1}$ Uni Cape Town/ International SOS, Cape Town, South Africa; ${ }^{2}$ University Cape Town, Cape Town, South Africa; ${ }^{3}$ LSTMH, London, United Kingdom; ${ }^{4}$ Aurum Health Institute, Johannesburg, South Africa

\subsection{6/oemed-2013-101717.78}

Objectives Against the background of an epidemic of silicosis and related tuberculosis revealed by field and autopsy studies in recent decades, the South African gold mining industry has committed itself to the elimination of silicosis.

Methods Annual chest radiographs of active miners were taken by mine occupational health services. These were collected in a representative sample of miners enrolled into a baseline survey between 2004 and 2009 as part of a cluster randomised trial of community-wide isoniazid preventive therapy. All radiographs were read for silicosis by an experienced lay reader. All images classified as abnormal and a random sample of normals was reread by a 'B' reader for validation.

Results A total of 14322 radiographs from 15 goldmining shafts from three companies were read by the lay reader for an overall silicosis prevalence of $3.7 \%$ (> ILO 1/1), reaching 6.6\% for workers with $>20$ years since first employment. Silicosis prevalences adjusted for the readings of the B-reader were much lower: 1.7\% and $3.2 \%$ respectively. On either reading, these industry-wide radiological prevalences are lower than single workforce surveys dating from 2000/2001. They are also at considerable variance with statutory autopsy data from in-service black miners.

Conclusions In the absence of evidence of lower dust levels in gold mines in the decades prior to this study, one explanation for these findings is that goldminers with silicosis are increasingly being selected out of the industry by ill-health, particularly HIV and tuberculosis, and/or by stricter hiring practices in a declining industry. High silicosis prevalence is thus likely still to be found among former goldminers. Autopsy data from active miners further suggest a shift towards sub-radiological silicosis, which has been shown to confer a substantially increased risk of tuberculosis even in the absence or radiological disease.

\section{UK BIOBANK: USE AND EXTENSION OF OCCUPATIONAL INFORMATION TO INVESTIGATE OCCUPATIONALLY- RELATED CHRONIC OBSTRUCTIVE PULMONARY DISEASE (COPD) IN THE UK}

'L Rushton, ${ }^{2}$ Sadhra, 'De-Matteis, 'Jarvis, ${ }^{3}$ Fishwick, ${ }^{4}$ Chambers, ${ }^{5}$ Mitchell, ${ }^{5}$ Gallacher, ${ }^{1}$ Wheatley, 'Hutchings, ${ }^{1}$ Cullinan. ${ }^{1}$ Imperial College London, London, United Kingdom; ${ }^{2}$ University of Birmingham, Birmingham, United Kingdom; ${ }^{3}$ University of Sheffield, Sheffield, United Kingdom; ${ }^{4}$ Health and Safety Laboratory, Buxton, United Kingdom; ${ }^{5}$ University of Cardiff, Cardiff, United Kingdom

10.1136/oemed-2013-101717.79 